\title{
Preoperative use of enoxaparin is not a risk factor for postoperative bleeding after coronary artery bypass surgery
}

\author{
Benjamin Medalion, $\mathrm{MD}^{\mathrm{a}}$ \\ George Frenkel, MD \\ Paulina Patachenko, MD \\ Eli Hauptman, MDa \\ Lior Sasson, MD \\ Arie Schachner, $M D^{\mathrm{a}}$
}

\footnotetext{
From the Departments of Cardiothoracic Surgery and Hematology, The Edith Wolfson Medical Center, Holon, Israel.

Received for publication Jan 7, 2003; revisions requested March 24, 2003; revisions received May 18, 2003; accepted for publication June 17, 2003.

Address for reprints: Benjamin Medalion, MD, Department of Cardiothoracic Surgery, The Edith Wolfson Medical Center, POB 5, Holon 58100, Israel (E-mail: medalion@wolfson.health.gov.il).

J Thorac Cardiovasc Surg 2003;126:1875-9

Copyright () 2003 by The American Association for Thoracic Surgery

$0022-5223 / 2003 \$ 30.00+0$

doi:10.1016/S0022-5223(03)01324-2
}

Background: The purpose of this study was to determine whether the use of low-molecular-weight heparin before coronary artery bypass surgery would be associated with an increase in bleeding and use of blood products after the operation.

Methods: Sixty-four patients (48 men and 16 women) aged $64 \pm 10$ years who were undergoing primary coronary artery bypass surgery were prospectively studied. Forty-one patients were treated with either subcutaneous enoxaparin $1 \mathrm{mg} / \mathrm{kg}$ twice daily $(n=21$; enoxaparin group) or intravenous heparin $(n=20$; heparin group). Patients received the last dose of enoxaparin $8.7 \pm 0.75$ hours (range, 8-10 hours) before skin incision. Heparin was stopped before transfer to the operating room. An additional 23 consecutive patients who received neither enoxaparin nor heparin served as controls $(\mathrm{n}=23)$. Anti-factor Xa activity, a measure of enoxaparin and heparin activity, was measured at the start of the operation in all patients.

Results: There was no perioperative mortality. The length of stay and frequency of postoperative complications were similar between groups. Preoperative anti-factor Xa activity was present only in the enoxaparin group $(0.43 \pm 0.25 \mathrm{IU} / \mathrm{mL})$. Chest tube drainage at 24 hours was $553 \pm 160 \mathrm{~mL}, 532 \pm 140 \mathrm{~mL}$, and $587 \pm 230 \mathrm{~mL}$ for the enoxaparin, heparin, and control groups, respectively $(P=.48)$. There was no difference among groups in the amount of blood products transfused.

Conclusions: Enoxaparin administration more than 8 hours before coronary artery bypass surgery is not associated with increased postoperative bleeding or blood product transfusion.

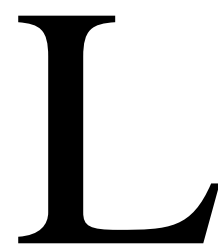
ow-molecular-weight heparins (LMWH) are considered to be a mainstay of therapy for patients with acute coronary syndromes. ${ }^{1}$ LMWH are fragments of unfractionated heparin that exert their anticoagulant activity by activating antithrombin. The activated antithrombin accelerates its interaction with thrombin and activated factor Xa. Unlike unfractionated heparin, which has equivalent activity against factor Xa and thrombin, LMWH have greater activity against factor $\mathrm{Xa}^{2} \mathrm{LMWH}$ produce a more predictable anticoagulant response than unfractionated heparin. ${ }^{3}$ Consequently, in contrast to patients treated with unfractionated heparin, laboratory monitoring is usually unnecessary for patients treated with LMWH. ${ }^{2}$ In addition to the better bioavailability and ease of use of LMWH, enoxaparin, an LMWH, has been shown to be superior to unfractionated heparin in the treatment of acute coronary syndrome. ${ }^{4-6}$ Therefore, patients with more urgent conditions who are waiting for coronary artery bypass graft surgery $(\mathrm{CABG})$ may be treated with LMWH before surgery. Because the LMWH duration of activity is longer than that of unfractionated heparin and is only partially neutralized by protamine sulfate, ${ }^{2,7}$ 
TABLE 1. Preoperative and operative characteristics

\begin{tabular}{|c|c|c|c|c|}
\hline Variable & $\begin{array}{c}\text { Enoxaparin } \\
(\mathrm{n}=21)\end{array}$ & $\begin{array}{l}\text { Heparin } \\
(n=20)\end{array}$ & $\begin{array}{c}\text { Control } \\
(n=23)\end{array}$ & $\begin{array}{c}P \\
\text { value }\end{array}$ \\
\hline Age (y) & $66.5 \pm 8.3$ & $64 \pm 12$ & $63 \pm 11$ & .58 \\
\hline $\operatorname{BSA}\left(\mathrm{m}^{2}\right)$ & $1.8 \pm 0.14$ & $1.85 \pm 0.14$ & $1.8 \pm 0.2$ & .74 \\
\hline Female sex & $5(24)$ & $5(25)$ & $6(26)$ & .99 \\
\hline Diabetes mellitus & $13(62)$ & $11(55)$ & $10(43)$ & .3 \\
\hline Hypertension & $12(57)$ & $13(65)$ & $14(61)$ & .89 \\
\hline Current smoker & $8(38)$ & $6(30)$ & $6(26)$ & .56 \\
\hline COPD & $1(5)$ & $1(5)$ & 0 & .54 \\
\hline History of CVA & $1(5)$ & $2(10)$ & 0 & .3 \\
\hline Creatinine $>2 \mathrm{mg} / 100 \mathrm{~mL}$ & $1(5)$ & $1(5)$ & $1(4)$ & .99 \\
\hline History of MI & $12(57)$ & $9(45)$ & $10(44)$ & 6 \\
\hline Unstable angina & $18(86)$ & $15(75)$ & $1(4)$ & $<.001$ \\
\hline $\operatorname{LVEF}(\%)$ & $54 \pm 12$ & $50 \pm 11$ & $54 \pm 10$ & .46 \\
\hline Left main disease & $3(14)$ & $7(35)$ & $5(18)$ & .29 \\
\hline Triple vessel disease & $13(62)$ & $11(55)$ & $14(61)$ & .96 \\
\hline Preoperative IABP & 0 & $6(30)$ & 0 & .001 \\
\hline No. of grafts & $3 \pm 1$ & $2.7 \pm 1$ & $3 \pm 1$ & .65 \\
\hline Double thoracic & $4(19)$ & $2(10)$ & $6(26)$ & .4 \\
\hline CPBt (min) & $116 \pm 31$ & $113 \pm 38$ & $122 \pm 40$ & .7 \\
\hline $\mathrm{XCt}(\min )$ & $81 \pm 23$ & $82 \pm 29$ & $87 \pm 24$ & .73 \\
\hline Heparin $(\mathrm{mg} / \mathrm{kg})$ & $5.4 \pm 0.54$ & $5.6 \pm 0.66$ & $5.3 \pm 0.95$ & .38 \\
\hline Protamine $(\mathrm{mg} / \mathrm{kg})$ & $4 \pm 0.6$ & $4.3 \pm 0.6$ & $4.4 \pm 1$ & .25 \\
\hline
\end{tabular}

Data are presented as mean \pm SD for continuous variables and as number of occurrences (\%) for noncontinuous variables. $B S A$, Body surface area; $C O P D$, chronic obstructive pulmonary disease; $C V A$, cerebrovascular accident; $M I$, myocardial infarction; $L V E F$, left ventricular ejection fraction; $I A B P$, intra-aortic balloon pump; CPBt, cardiopulmonary bypass time; $X C t$, crossclamp time.

we wanted to find out whether the use of LMWH before CABG is associated with an increase in postoperative bleeding and use of blood products.

\section{Patients and Methods}

The study was approved by the hospital ethics committee, and written, informed consent was obtained from all patients. Sixtyfour patients undergoing primary CABG were prospectively studied. Forty-one patients with urgent conditions were treated with either subcutaneous enoxaparin $1 \mathrm{mg} / \mathrm{kg}$ twice daily $(\mathrm{n}=21$; enoxaparin group) or intravenous unfractionated heparin $(n=20$; heparin group). Patients received the last dose of enoxaparin at midnight before their operation if they received their operation in a morning session or at 7:00 AM if they underwent operation in an afternoon session. The average time between the last enoxaparin injection and operation was $8.7 \pm 0.75$ hours (range, $8-10$ hours) before skin incision. Unfractionated heparin was discontinued before transfer to the operating room. Patients were assigned to enoxaparin or heparin groups according to the primary physician preference. Twenty-three consecutive elective patients who received neither LMWH nor unfractionated heparin served as a control group. Anti-factor Xa activity, a measure of LMWH and unfractionated heparin activity, was measured at the start of the operation (skin incision) in all patients by a chromogenic assay (Berichrom Heparin; Dade Behring Marburg GmbH, Marburg, Germany).

All patients received aspirin until the day of the operation. The operation was performed via a median sternotomy in a standard fashion for all patients. The left internal thoracic artery was used in all cases and harvested first, followed by the right internal thoracic artery, when used. The left radial artery was harvested simultaneously with the saphenous vein, when needed. Cardiopulmonary bypass was achieved with aortic and single venous cannulae. The patients were uniformly cooled to $32^{\circ} \mathrm{C}$. Cardioplegia was achieved with antegrade and retrograde cold blood cardioplegia with repeated doses every 20 minutes. All distal anastomoses were performed first, and proximal anastomoses were performed during the same crossclamp while the heart was perfused retrogradely with warm blood. The mediastinal and left chest were routinely drained, and the right chest was drained only when the right pleura was opened. The activated clotting time values were kept between 500 and 600 seconds during the bypass period.

Continuous variables are expressed as mean \pm SD. Noncontinuous data are expressed as number of events and percentage. For statistical analysis, 1-way analysis of variance was used for normally distributed continuous variables, the Kruskal-Wallis nonparametric test for abnormally distributed variables, and the $\chi^{2}$ test for categorical variables. Linear regression analysis was used to search for associations between anti-factor Xa activity and postoperative bleeding. To calculate the necessary sample size for the study, a power analysis for analysis of variance was performed. We defined a difference of at least $200 \mathrm{~mL}$ of chest tube drainage between groups with a pooled SD of $230 \mathrm{~mL}$ to be of clinical importance. To achieve an $80 \%$ power to detect such a difference with an $\alpha$ of $.05,20$ patients were calculated to be required for each group.

\section{Results}

Preoperative and operative data are presented in Table 1. More patients in the enoxaparin and heparin groups had 
unstable angina compared with the control group. An intraaortic balloon pump was present before surgery in 6 patients, all in the heparin group. No differences were observed with regard to type of graft used, number of grafts per patient, cardiopulmonary bypass, and crossclamp time. There was no difference among groups in preoperative laboratory values reflecting liver or kidney function. There was no perioperative mortality, and the length of stay and frequency of postoperative complications were similar among groups (Table 2). Although a postoperative increase in serum creatinine was common, renal failure (defined as serum creatinine $\geq 2 \mathrm{mg} / 100 \mathrm{~mL}$ ) was present only in those patients who had preoperative serum creatinine $\geq 2 \mathrm{mg} / 100$ $\mathrm{mL}$. Only 1 patient, in the heparin group, required temporary hemodialysis. Four patients had postoperative infection that required administration of antibiotics.

Preoperative and postoperative coagulation profiles and hemoglobin were similar among groups, except for preoperative heparin activity (anti-factor Xa activity), which was documented only in the enoxaparin group (Table 3 ). There was no significant difference among the groups in the amount of mediastinal bleeding during the first 24 hours after the operation or in the amount of blood products transfused during the hospital stay (Table 4). Moreover, a linear regression analysis demonstrated no correlation between preoperative anti-factor $\mathrm{Xa}$ activity and 24-hour postoperative bleeding $(r=0.16 ; P=.22)$.

\section{Discussion}

In the current era of cardiology, in which several potent antithrombotic and antiplatelet agents are used for a variety of indications, cardiac surgeons are faced with an increasing number of patients who are referred to operation while being treated with one or more of those agents. Because patients may bleed after cardiac surgery, a decision has to be made regarding the proper timing of the operation. Enoxaparin, an LMWH, is commonly used in cardiac patients. It has a longer duration of action than unfractionated heparin and is only partially neutralized by protamine sulfate. ${ }^{2,7}$ Therefore, a bleeding tendency after CABG may be anticipated. In this study, we asked whether enoxaparin given before urgent CABG was associated with an increased tendency for postoperative bleeding or blood product transfusion. We showed that if the last dose of enoxaparin was given $8.7 \pm 0.75$ hours before operation, then the blood loss and blood products transfused were similar between those who received enoxaparin and those who did not. Jones and colleagues $^{8}$ retrospectively studied 1159 patients who received either unfractionated heparin or enoxaparin within 48 hours of $\mathrm{CABG}$, and they found higher incidence of re-exploration for bleeding after enoxaparin administration. They could not show any difference in the amount of blood loss or blood products transfused between those who re-
TABLE 2. Length of stay and postoperative complications

\begin{tabular}{lcccc}
\hline Variable & $\begin{array}{c}\text { Enoxaparin } \\
(\mathbf{n}=\mathbf{2 1})\end{array}$ & $\begin{array}{c}\text { Heparin } \\
(\mathbf{n}=\mathbf{2 0})\end{array}$ & $\begin{array}{c}\text { Control } \\
(\mathbf{n}=\mathbf{2 3})\end{array}$ & $\boldsymbol{P}$ value \\
\hline Length of stay (d) & $6.7 \pm 4$ & $7.1 \pm 5$ & $6.7 \pm 4.2$ & .95 \\
Perioperative MI & 0 & 0 & 0 & \\
CVA & 0 & 0 & 0 & \\
Cr $>2 \mathrm{mg} / 100 \mathrm{~mL}$ & $1(5)$ & $1(5)$ & $1(4)$ & .99 \\
Dialysis & 0 & $1(5)$ & 0 & .3 \\
Infection & $1(5)$ & $1(5)$ & $2(9)$ & .83 \\
\hline
\end{tabular}

Data are presented as mean $\pm S D$ for continuous variables and as number of occurrences (\%) for noncontinuous variables. MI, Myocardial infarction; CVA, cerebrovascular accident; $\mathrm{Cr}$, plasma creatinine.

ceived enoxaparin and those who received unfractionated heparin. ${ }^{8}$ Of concern is the lack of correlation between the increased reexploration rate and bleeding or blood products transfused. In addition, there is no temporal relationship between the last dose of enoxaparin administration and postoperative bleeding or likelihood of re-exploration. It may well be that those who were re-explored received the last enoxaparin dose shortly before the operation. In contrast, Clark and associates, ${ }^{9}$ who performed a prospective study on 390 patients and investigated the influence of dalteparin, a different type of LMWH, on postoperative bleeding after cardiac surgery, did not find an increase in the re-exploration rate but found that patients who received dalteparin less than 12 hours before operation had an increase in blood loss and blood transfusion. Skubas and associates ${ }^{10}$ described a patient who bled $2360 \mathrm{~mL}$ during the first 24 hours after CABG. This patient received enoxaparin on the day of operation and also received tirofiban, a short-acting IIb/IIIa platelet glycoprotein receptor inhibitor, which was discontinued the night before operation. In all of these studies, anti-factor Xa activity was not measured, so a reliable measure of heparin activity at the start of the operation is lacking. The sporadic use of LMWH as an anticoagulant during cardiopulmonary bypass has been shown to be associated with increased postoperative bleeding. ${ }^{11,12}$ It may well be that the patients who bled or were re-explored in these studies ${ }^{8-10}$ had high anti-factor Xa activity during the operation and, as a result, had a higher tendency to bleed or to be re-explored.

In this study, preoperative heparin activity, measured by anti-factor Xa activity, was documented only in the group of patients who received enoxaparin. Patients who received unfractionated heparin did not show anti-factor Xa activity and had activated partial thromboplastin times within normal range at the start of the operation. Whether this finding reflects the short half-life of this product-so that by the time the patient arrived at the operating room it was eliminated from the blood-or whether the patients were not properly treated with unfractionated heparin before the operation is not known. 
TABLE 3. Preoperative and postoperative hemoglobin and coagulation profile

\begin{tabular}{|c|c|c|c|c|}
\hline Variable & $\begin{array}{c}\text { Enoxaparin } \\
(n=21)\end{array}$ & $\begin{array}{l}\text { Heparin } \\
(n=20)\end{array}$ & $\begin{array}{c}\text { Control } \\
(n=23)\end{array}$ & $P$ value \\
\hline \multicolumn{5}{|l|}{ Before surgery } \\
\hline $\mathrm{Hb}(\mathrm{mg} / 100 \mathrm{~mL})$ & $11.2 \pm 1.3$ & $11.4 \pm 1.4$ & $11.4 \pm 1.5$ & .86 \\
\hline Platelets $\left(\times 10^{3} / \mathrm{mL}\right)$ & $208 \pm 49$ & $225 \pm 59$ & $194 \pm 50$ & .18 \\
\hline INR & $1.1 \pm 0.08$ & $1.1 \pm 0.07$ & $1.1 \pm 0.07$ & .43 \\
\hline aPTT (s) & $32 \pm 7$ & $31 \pm 6$ & $29 \pm 4$ & .39 \\
\hline Anti-factor Xa (IU/mL) & $0.43 \pm 0.25$ & $0.09 \pm 0.07$ & $0.05 \pm 0.07$ & $<.001$ \\
\hline \multicolumn{5}{|l|}{$24 \mathrm{~h}$ after surgery } \\
\hline $\mathrm{Hb}(\mathrm{mg} / 100 \mathrm{~mL})$ & $10 \pm 0.9$ & $10.4 \pm 1$ & $10.2 \pm 0.9$ & .3 \\
\hline Platelets $\left(\times 10^{3} / \mathrm{mL}\right)$ & $149 \pm 55$ & $161 \pm 58$ & $136 \pm 55$ & .36 \\
\hline INR & $1.2 \pm 0.12$ & $1.2 \pm 0.2$ & $1.2 \pm 0.11$ & .71 \\
\hline aPTT (s) & $29 \pm 2.8$ & $30 \pm 5.4$ & $29 \pm 3.3$ & .79 \\
\hline \multicolumn{5}{|l|}{ At discharge } \\
\hline $\mathrm{Hb}(\mathrm{mg} / 100 \mathrm{~mL})$ & $10.8 \pm 0.6$ & $11 \pm 0.7$ & $10.5 \pm 1$ & .4 \\
\hline
\end{tabular}

Data are presented as mean \pm SD. $H b$, Hemoglobin; INR, international normalized ratio; $a P T T$, activated partial thromboplastin time.

TABLE 4. Blood loss and blood products transfused

\begin{tabular}{|c|c|c|c|c|}
\hline Variable & $\begin{array}{c}\text { Enoxaparin } \\
(\mathrm{n}=21)\end{array}$ & $\begin{array}{l}\text { Heparin } \\
(n=20)\end{array}$ & $\begin{array}{l}\text { Control } \\
(n=23)\end{array}$ & $P$ value \\
\hline 24-h bleeding $(\mathrm{mL})$ & $553 \pm 160$ & $532 \pm 140$ & $587 \pm 230$ & .48 \\
\hline $\operatorname{PRBC}(U)^{*}$ & $1(0-3)$ & $1(0-2)$ & $1(0-3)$ & .65 \\
\hline $\mathrm{FFP}(\mathrm{U})^{*}$ & $0(0-2)$ & $0(0-2)$ & $0(0-2)$ & .83 \\
\hline Platelets (U)* & $0(0-6)$ & 0 & $0(0-6)$ & .25 \\
\hline No. transfused* & $13(62)$ & $12(60)$ & $16(70)$ & .82 \\
\hline
\end{tabular}

Data are presented as mean \pm SD for bleeding, as number of occurrences (\%) for number transfused, and as median (range) for PRBC, FFP, and platelets. $P R B C$, Packed red blood cells; FFP, fresh frozen plasma.

*During hospital stay.

Peak anti-factor Xa activity after subcutaneous LMWH administration occurs within 3 to 4 hours, and the antifactor Xa levels are approximately $50 \%$ of peak levels 12 hours later. ${ }^{13}$ The mean anti-factor Xa activity at the start of the operation in this study was $0.43 \pm 0.25 \mathrm{IU} / \mathrm{mL}$ for the patients who received enoxaparin. Although enoxaparin activity is still present, the level of activity only approaches the therapeutic range of 0.5 to $1.1 \mathrm{IU} / \mathrm{mL} .{ }^{14}$ The subtherapeutic levels of anti-factor Xa activity found $8.7 \pm 0.75$ hours after the last dose of enoxaparin may explain why patients in this study did not show an increased tendency of bleeding in the enoxaparin group.

Usually enoxaparin is administered twice daily. Because most patients treated with enoxaparin do not need to proceed directly to operation on an emergency basis, there should be no need to modify the timing of the operation or to prematurely discontinue enoxaparin.

Heparin resistance requiring the administration of antithrombin III or fresh frozen plasma during cardiopulmonary bypass to achieve appropriate activated clotting time was not documented in this study. In the literature it was identified in up to $26 \%$ of patients undergoing cardiac surgery and was shown to be associated with preoperative use of unfractionated heparin. ${ }^{15}$ No data are available regarding heparin resistance and preoperative use of LMWH. The absence of heparin resistance with preoperative use of enoxaparin in this study may imply that it is not more prevalent than the resistance experienced after preoperative use of unfractionated heparin. However, a larger study designed to answer this question is required to make such a conclusion.

Although this is a prospective study, it was not blinded, and the decision about whether a patient would receive enoxaparin or unfractionated heparin was the primary physician's decision according to his or her preference. The patient population was not homogeneous among groups, and the sample size in this study was small. Nevertheless, because the differences among groups in chest tube drainage were not statistically different or of any clinical importance (defined as chest tube drainage of more than $200 \mathrm{~mL}$ for 24 hours), the results seem valid. Enoxaparin was administered 8 to 10 hours before operation, and no conclusion or recommendation can be made if the interval between the last enoxaparin dose and operation is less than 8 hours. Larger prospective studies need to be performed to clarify the contrasting data regarding the re-exploration rate after LMWH administration before CABG. Until such studies are 
available, clinicians may consider discontinuing the use of these agents and initiating the use of unfractionated heparin at least 24 to 48 hours before operation.

In conclusion, in this small series of patients at low risk for postoperative bleeding, enoxaparin administration more than 8 hours before $\mathrm{CABG}$ proved not to be associated with increased postoperative bleeding or blood product transfusion.

We thank Nurit Ben-Yosef, MSc, who carefully analyzed the anti-factor Xa activity assay.

\section{References}

1. Turpie AG, Antman EM. Low-molecular-weight heparins in the treatment of acute coronary syndromes. Arch Intern Med. 2001;161:148490.

2. Weitz JI. Low-molecular-weight heparins. N Engl J Med. 1997;337: 688-98.

3. Handeland GF, Abildgaard U, Holm HA, Arnesen KE. Dose adjusted heparin treatment of deep venous thrombosis: a comparison of unfractionated and low molecular weight heparin. Eur J Clin Pharmacol. 1990;39:107-12.

4. Cohen M, Demers C, Gurfinkel EP, Turpie AG, Fromell GJ, Goodman $\mathrm{S}$, et al. A comparison of low-molecular-weight heparin with unfractionated heparin for unstable coronary artery disease. Efficacy and Safety of Subcutaneous Enoxaparin in Non-Q-Wave Coronary Events Study Group. N Engl J Med. 1997;337:447-52.

5. Antman EM, McCabe CH, Gurfinkel EP, Turpie AG, Bernink PJ, Salein D, et al. Enoxaparin prevents death and cardiac ischemic events in unstable angina/non-Q-wave myocardial infarction. Results of the thrombolysis in myocardial infarction (TIMI) 11B trial. Circulation. 1999;100:1593-601.

6. Antman EM, Cohen M, Radley D, McCabe C, Rush J, Premmereur J, et al. Assessment of the treatment effect of enoxaparin for unstable angina/non-Q-wave myocardial infarction. TIMI 11B-ESSENCE meta-analysis. Circulation. 1999;100:1602-8.

7. Holst J, Lindblad B, Bergqvist D, Garre K, Nielsen H, Hedner U, et al. Protamine neutralization of intravenous and subcutaneous low-molecular-weight heparin (tinzaparin, Logiparin). An experimental investigation in healthy volunteers. Blood Coagul Fibrinolysis. 1994;5:795803.

8. Jones HU, Muhlestein JB, Jones KW, Bair TL, Lavasani F, Sohrevardi $\mathrm{M}$, et al. Preoperative use of enoxaparin compared with unfractionated heparin increases the incidence of re-exploration for postoperative bleeding after open-heart surgery in patients who present with an acute coronary syndrome: clinical investigation and reports. Circulation. 2002;106:I19-22.

9. Clark SC, Vitale N, Zacharias J, Forty J. Effect of low molecular weight heparin (fragmin) on bleeding after cardiac surgery. Ann Thorac Surg. 2000;69:762-4.

10. Skubas NJ, Despotis GJ, Vlasnic JJ, Moon MR. Preoperative use of enoxaparin and tirofiban: possible association with increased bleeding postbypass. Anesthesiology. 1999;91:869-72.

11. Massonnet-Castel S, Pelissier E, Dreyfus G, Deloche A, Abry B, Guibourt $\mathrm{P}$, et al. Low-molecular-weight heparin in extracorporeal circulation. Lancet. 1984;1:1182-3.

12. Massonnet-Castel S, Pelissier E, Bara L, Terrier E, Abry B, Guibourt $\mathrm{P}$, et al. Partial reversal of low molecular weight heparin (PK 10169) anti-Xa activity by protamine sulfate: in vitro and in vivo study during cardiac surgery with extracorporeal circulation. Haemostasis. 1986;16: $139-46$.

13. Hirsh J, Levine MN. Low molecular weight heparin: laboratory properties and clinical evaluation. A review. Eur J Surg Suppl. 1994;9-22.

14. Dose-ranging trial of enoxaparin for unstable angina: results of TIMI 11A. The Thrombolysis in Myocardial Infarction (TIMI) 11A Trial Investigators. J Am Coll Cardiol. 1997;29:1474-82.

15. Ranucci M, Isgro G, Cazzaniga A, Soro G, Menicanti L, Frigiola A. Predictors for heparin resistance in patients undergoing coronary artery bypass grafting. Perfusion. 1999;14:437-42. 